\title{
EL EMPLEO EN LAS COOPERATIVAS DE TRABAJO ASOCIADO: ¿DERECHO AL TRABAJO O FACTOR PRODUCTIVO?
}

\author{
Aitor Bengoetxea Alkorta \\ Profesor de Derecho del Trabajo y de la Seguridad Social (UPV/EHU) \\ Director de GEZKI \\ (Gizarte Ekonomia eta Zuzenbide Kooperatiboaren Institutua / \\ Instituto de Derecho Cooperativo y Economía Social)
}

DOI: $10.1387 /$ lan-harremanak. 15393

\section{ABSTRACT}

Las sociedades capitalistas y las sociedades cooperativas muestran una naturale$z a$ distinta. Las primeras giran en torno al capital que les da vida, y las segundas son personalistas; las personas cooperativistas tienen primacia con respecto al capital que aportan.

La diferencia es evidente en el ámbito de las decisiones empresariales. En las sociedades capitalistas, los votos se distribuyen en proporción al capital aportado. En las cooperativas, impera el clásico principio de una persona, un voto.

Las situaciones de crisis afectan por igual a ambos tipos de empresa. Sin embargo, la respuesta, con respecto al empleo, es diferente. En las sociedades de capital, el Derecho del Trabajo ofrece una variada gama de medidas para afrontar las situaciones de crisis, algunas de flexibilidad interna (movilidad funcional, reducción de jornada, suspensión contractual, etc.), y también el despido, una más de las posibilidades de la empresa. 
En las cooperativas, el Derecho Cooperativo deja claro que la baja obligatoria de las personas socias-trabajadoras (equivalente al despido), solo procederá como última ratio, cuando las medidas de flexibilidad interna se muestren insuficientes y sea necesario para garantizar la viabilidad futura de la empresa.

Al tratar el despido como una medida supeditada a la obtención de beneficios, el Derecho del Trabajo trata el empleo como un mero factor productivo. El Derecho Cooperativo, sin embargo, al considerar la pérdida de empleo como último recurso, está preservando su carácter de derecho social.

Palabras clave: cooperativa, sociedad de capital, empleo, despido, Derecho del Trabajo, Derecho Cooperativo.

Capital companies and cooperative societies show a different nature. The first are based on the capital that gives them life, and the latter are personalistic; cooperativists have primacy over the capital they provide.

The difference is evident in the area of business decisions. In capital companies, the votes are distributed in proportion to the contributed capital. In cooperatives, prevails the classic principle of one person, one vote.

Crisis situations hit equally to both types of company. However, the response with regard to employment, is different. In capital companies, labour law provides a range of measures to tackle the crisis, some of internal flexibility (functional mobility, reducing working hours, contract suspension, etc.), and also the dismissal, just one more of the possibilities that the company may consider.

In cooperatives, cooperative law makes clear that the compulsory leave of membersworkers (equivalent to dismissal), proceed only as last resort, when the internal flexibility measures are insufficient, and compulsory leave seems needed to ensure the future viability of the company.

By treating the dismissal as a measure usable to make profits, employment is a mere productive factor for labour law. The cooperative law, however, when considering the loss of employment as a last resort, is preserving its character as a social right.

Key Words: cooperative, capital company, employment, dismissal, labour law, cooperative law.

Sozietate kapitalistek eta sozietate kooperatiboek izaera desberdina dute. Lehenek kapitala dute ardatz, eta bigarrenak pertsonalistak dira; kooperatibistek lehentasuna dute jartzen duten kapitalaren aurretik. 
Desberdintasuna nabarmena da enpresako erabakien arloan. Sozietate kapitalistetan, botoak kapital ekarpenen arabera banatzen dira. Kooperatibetan, pertsona bat, boto bat, printzipio klasikoa aplikatzen da.

Krisi egoerek berdin kolpatzen dituzte bi enpresa motak. Baina erantzuna, enpleguari dagokionez, desberdina da. Kapital sozietateetan, Lanaren Zuzenbideak krisiari aurre egiteko neurri sorta zabala eskaintzen du, batzuk barne malgutasunekoak (mugigarritasun funtzionala, lanaldi murrizketa, kontratuaren suspentsioa, etab.), eta baita ere kaleratzea, enpresak dituen aukeren artean, beste bat.

Kooperatibetan, Zuzenbide Kooperatiboak garbi uzten du bazkide-langileen derrigorrezko baja (kaleratzearen baliokidea), soilik última ratio edo azken aukera izango dela, barne malgutasuneko neurriak nabikoak ez direnean, eta beharrezkoa baldin bada enpresaren etorkizuneko bideragarritasuna bermatzeko.

Kaleratzea mozkinak lortzearen menpeko neurritzat jotzerakoan, Lanaren Zuzenbideak enplegua ekoizpen baliabide huts gisa tratatzen du. Zuzenbide Kooperatiboa, aitzitik, enplegua galtzea azken neurri gisa aurreikusten duenean, bere gizarte eskubide izaera babesten ari da.

Hitz gakoak: kooperatiba, kapital-sozietatea, enplegua, kaleratzea, Lanaren Zuzenbidea, Zuzenbide Kooperatiboa 


\section{Introducción}

El elemento central de este estudio plantea comparar, ante la crisis que estamos viviendo, cómo están respondiendo las sociedades capitalistas, el modelo de las sociedades capitalistas, sociedades anónimas o sociedades limitadas básicamente, y, por otra parte, cómo están respondiendo las sociedades cooperativas. Ese contraste es el hilo conductor de este trabajo.

¿Qué están haciendo uno y otro modelo empresarial? ¿Qué pueden hacer, jurídicamente, qué medidas pueden adoptar frente a la crisis con los instrumentos que ofrece el derecho laboral, en el caso de las sociedades capitalistas, y, con respecto a las cooperativas, en virtud de las disposiciones del Derecho Cooperativo? Se trata de comparar el catálogo jurídico de ambos modelos.

El estudio analiza medidas de flexibilidad interna y externa, siguiendo la terminología económica al uso, de manera que en la flexibilidad interna encontramos distintas medidas con el elemento en común de que no se pierda el empleo, y en la flexibilidad externa, por lo contrario, se pierde el empleo.

En derecho, a veces parece que se expresan las cosas más para que no se entiendan que para que se entiendan. En algunos momentos históricos ha sido así. Se trataba de que no fueran accesibles a todo el mundo los instrumentos del poder, en torno a los que giraba el derecho. Aquí nos encontramos con un buen ejemplo de todo lo contrario. En este caso el derecho es claro y cristalino, podríamos decir. Hay una ley que se llama ley de sociedades de capital. Se puede decir más alto pero no más claro. Es una sociedad que se vertebra en torno al capital, que es el que le da vida, el que da sentido a ese tipo de empresa. Sociedades de capital, donde el ingrediente principal es el capital y el resto es accesorio.

Por otro lado, tenemos las sociedades cooperativas, donde el nombre refleja el elemento de la cooperación y el eje son las personas. La doctrina mercantil las califica como sociedades personalistas, se basan por lo tanto en las personas, en la cooperación entre las personas.

Más allá de este contraste terminológico, creo que el reflejo más contundente de la diferente naturaleza de las sociedades de capital y las sociedades coo- 
perativas, es el hecho de que en las primeras los votos se distribuyan en función del capital y en las segundas, al ser personalistas, los votos se distribuyen en función de las personas con arreglo al conocido principio de una persona, un voto.

\section{El empleo en las sociedades de capital y en las sociedades cooperativas}

En cuanto al empleo, conviene subrayar la distinción del empleo en las sociedades capitalistas y en las sociedades cooperativas. En las primeras el empleo que hay es de personal asalariado, al que se aplica el Derecho del Trabajo. Las sociedades capitalistas contratan personas asalariadas. No hay otra posibilidad, en cuanto a plantilla interna al menos. Después está el tema de la externalización, pero cuando hablamos directamente del empleo dentro de una sociedad capitalista, solo puede ser personal asalariado al que se aplica el Derecho del Trabajo.

En las sociedades cooperativas, hay que comenzar por matizar que cuando se estudia el régimen jurídico de las sociedades cooperativas tenemos en el Estado español una ley de cooperativas para cada comunidad autónoma, excepto en las Islas Canarias que, pudiendo hacerlo, no han promulgado una ley de cooperativas propia. Este estudio se basa en la ley de cooperativas de la Comunidad Autónoma Vasca, que además fue la primera y que ha sido referencia para las siguientes.

De acuerdo con la mencionada ley vasca de cooperativas (Ley 4/1993, de 24 de junio, que ha conocido diversas modificaciones), en las sociedades cooperativas tenemos dos tipos de personal empleado. Por una parte, está el personal socio-trabajador, al que se aplica el Derecho Cooperativo. Se trata de personas socias-trabajadoras, que son personas — aquí la clave está en el guión-, socias y trabajadoras al mismo tiempo. Socias porque aportan capital a la empresa y son copropietarias de la misma. Además, son trabajadoras, porque trabajan en la propia empresa.

El segundo tipo es el personal asalariado. El Derecho del Trabajo define a las personas trabajadoras en términos muy amplios. Y, en este caso, simplemente hay que decir que cuando en una cooperativa hay personal asalariado, a esa cooperativa se le aplica el Derecho del Trabajo como a cualquier otra empresa convencional. Cuando tiene personal asalariado, la cooperativa es una empresa al uso. En este caso no se observa ninguna peculiaridad cooperativa y el derecho permite que haya personal asalariado. Solo hay un límite cuantitativo, en virtud del cual el personal asalariado puede trabajar, del total de trabajo de la cooperativa, un máximo del $25 \%$ de horas al ańo. 
Aunque el derecho positivo cooperativo actualmente permita personal asalariado, se trata de una cuestión ciertamente discutible. Es una cuestión de principios. Si es una cooperativa ¿por qué integrar personas trabajadoras, cuyo régimen jurídico se basa en el conflicto capital-trabajo? El personal asalariado en una cooperativa es un elemento de distorsión jurídica y de funcionamiento de la misma.

Cabe mencionar un caso ciertamente muy interesante. Se trata de la cooperativización de una sociedad capitalista, sociedad anónima, en crisis. La misma persona que había sido presidente del Comité de Empresa y conoció de primera mano la crisis y el declive empresarial, cuando se transforma en cooperativa, se convierte en presidente del Consejo Rector. Esa persona cuenta que el proceso fue muy complejo, pero se vio coronado con el éxito. Y una de las cuestiones que subraya es que, en las asambleas, los cooperativistas, utilizando la imaginación, la solidaridad y el sacrificio, adoptaban muchas medidas para sacar adelante la cooperativa, en pro de su viabilidad económica, y mediante el mutuo compromiso.

Pero cuando los cooperativistas iban a hablar con los trabajadores asalariados de la cooperativa, les decían: "A nosotros, aplicadnos el convenio colectivo". Este ejemplo creo que es de mucho calado, y que ayuda a sostener la idea de que es perjudicial, y debería evitarse, la presencia de personal asalariado en las cooperativas.

La clave no estriba en las personas, sino en los modelos jurídicos. La existencia de personal asalariado en una cooperativa es realmente una distorsión per se. Y si podemos evitar a priori — aunque después las dinámicas empresariales son complejas - un elemento que con mucha probabilidad sabemos que va a proporcionar distorsión, deberíamos hacerlo.

\section{Medidas que cabe adoptar ante situaciones de crisis}

Se trata de estudiar cómo responden las sociedades de capital y las sociedades cooperativas ante la crisis. Para ello, hay que analizar, según el derecho, qué es crisis y cuáles son las distintas medidas frente a la crisis. Para el estudio jurídico de qué se entiende por crisis hay que acudir al Derecho Laboral, porque el Derecho Cooperativo apenas lo desarrolla.

Cuando la ley de cooperativas se enfrenta a la cuestión de la crisis económica de una cooperativa, normalmente utiliza categorías importadas del Derecho Laboral.

Cuando hablamos de crisis, el Derecho del Trabajo distingue causas económicas, técnicas, organizativas o de producción. Muchas veces se utiliza como si 
fuera un bloque cuyo contenido no tiene demasiado interés, o no está muy claro el deslinde de las cuatro figuras. Pero hay que tratar de diferenciar los cuatro elementos en ese concepto global de crisis, que en el fondo es un convencionalismo. En realidad la legislación laboral no utiliza el término crisis.

Las causas económicas tienen que ver, desde luego, con el dinero. Tenemos resultados en una empresa, de los cuales se desprende una situación económica negativa, pérdidas actuales o previstas, disminución persistente del nivel de ingresos o ventas. En todo caso, se entenderá que la disminución de ingresos o de ventas es persistente si se produce durante tres trimestres consecutivos. $\mathrm{O}$ sea, si una empresa, durante tres trimestres consecutivos, tiene una bajada de ventas, se entendería técnicamente que está en dificultades económicas aunque siga teniendo beneficios.

Desde luego, no se trata de una interpretación sesuda ni aguda. Simplemente refleja la gran flexibilidad y facilidad que otorga la ley para que se entienda que una empresa está en dificultades económicas aunque tenga beneficios.

Cuando se habla de causas técnicas y de causas organizativas, las técnicas tendrían que ver con los instrumentos materiales de producción, con el factor capital en la terminología marxista clásica y las causas organizativas tendrían que ver con el factor trabajo. Problemas, disfunciones en el factor capital o problemas en el factor trabajo. Las causas serán técnicas, cuando se produzcan cambios, por lo tanto, en el ámbito de los instrumentos de producción.

Las causas productivas suelen girar en torno a una reducción en la demanda de los productos o servicios de la empresa. Este ha sido, sin ninguna duda, el principal supuesto de hecho de la crisis económica que vivimos. Muchas empresas se han visto ahogadas porque no tenían a quién vender sus productos o servicios.

Así pues, cuando hablamos de crisis, hablamos de causas económicas, técnicas, organizativas o de producción en los términos que he intentado plantear. Pasemos al contraste de qué puede hacer una empresa capitalista o una cooperativa ante estas situaciones de crisis.

Comenzando por la empresa capitalista, a la que se aplica el Derecho del Trabajo, nos encontramos con la medida de la movilidad funcional, que consiste en un cambio de funciones. A una o a varias personas asalariadas se les cambian las funciones y así se ajusta la organización a las necesidades de la empresa, corrigiendo la crisis surgida en la misma. Si se cambian las funciones de una persona o de unas personas dentro de su grupo profesional, no hay límite temporal, se pueden cambiar las funciones incluso indefinidamente. Si son funciones que corresponden a un grupo profesional superior o inferior solo podría hacerse por el tiempo imprescindible. 
¿En las cooperativas puede haber movilidad funcional? ¿Una cooperativa puede superar su crisis cambiando de funciones a algunas personas cooperativistas? Por supuesto que sí ¿Cuál es el régimen jurídico? Podemos expresarlo mediante una sola palabra: autogestión. Las personas cooperativistas analizan el problema y pueden decidir — entre otras muchas posibilidades - la movilidad funcional. ¿En qué términos? En los que quieran. En los que decida la asamblea mayoritariamente, con el único límite, si lo hubiera, de las previsiones de los estatutos y del régimen jurídico interno de la cooperativa.

Otra medida para salir adelante de un supuesto de crisis es la denominada movilidad geográfica, que consiste en cambiar a las personas de centro de trabajo. Obviamente esto solo puede suceder en grandes empresas que tienen varios centros de trabajo, de manera que hay centros de trabajo con más producción que otros y entonces hay un reajuste, moviendo unas personas de un centro de trabajo a otro. El Derecho del Trabajo tiene un régimen bastante detallado, donde hay que compensar los gastos de traslado. Además, cualquier persona puede negarse y recibir una indemnización de 20 días de salario por año de servicio.

En las cooperativas, ¿puede haber movilidad geográfica? Sí. Si es una gran cooperativa con distintos centros, puede hacerlo. ¿En qué términos? En los que libremente decida la asamblea. La ley de cooperativas nada establece al respecto. $\mathrm{La}$ asamblea solo resulta vinculada por los estatutos y por el régimen jurídico interno de la cooperativa.

Otra medida sería la modificación sustancial de condiciones de trabajo. La empresa unilateralmente entiende que la situación es insostenible. Entonces la empresa plantea superar esa situación cambiando algunas condiciones de trabajo que se entienden sustanciales: salario, jornada, horario, funciones, etc. En el caso de funciones sería un cambio todavía más profundo que la mera movilidad funcional. Por ejemplo, un cambio a funciones de inferior grupo profesional de carácter definitivo. En este supuesto de modificaciones sustanciales, hay que subrayar la novedad de la posibilidad de que la empresa unilateralmente baje el salario. Novedad introducida en la reforma de 2012.

Una cooperativa puede proceder a modificar sustancialmente las condiciones de trabajo de las personas socias-trabajadoras con total flexibilidad. Otra vez, la cuestión queda en manos de la asamblea de cooperativistas.

Otra medida que prevé el Derecho Laboral es el descuelgue del convenio aplicable. Una empresa, a pesar de tener un convenio firmado, vigente y aplicable, tiene la posibilidad de no aplicarlo, porque entiende que no puede garantizar las condiciones del convenio. Hay que intentar un acuerdo con la parte trabajadora. $\mathrm{Y}$ el proceso puede terminar en un árbitro que decida si realmente hay o no motivos para no aplicar el convenio. 
Este es un caso no trasladable al Derecho Cooperativo. El Derecho Cooperativo tiene que respetar siempre los estatutos, y no hay convenios colectivos. Por consiguiente, este caso no sería comparable.

Otra medida que el Derecho Laboral prevé es la reducción de jornada. Esto es lo que antes se establecía mediante EREs que la autoridad laboral debía aprobar. Y ahora la empresa unilateralmente puede establecerlo y a los trabajadores y trabajadoras solo les queda la impugnación ante el juez. Reducción de jornada para hacer frente normalmente al supuesto que veíamos de la menor demanda de productos o servicios de la empresa. La empresa responde ajustando la capacidad de la plantilla con una disminución temporal de la jornada de determinadas personas, entre un mínimo de un $10 \%$ y un máximo del $70 \%$ de la jornada de trabajo. En este caso, las personas afectadas sufren una reducción proporcional de salario que se ve compensada con la prestación por desempleo. Reducción parcial de la jornada, y correspondiente desempleo parcial.

En el caso de las cooperativas también pueden, sin ninguna duda, proceder a este tipo de medidas de reducción de jornada, otra vez, en los términos que decida la asamblea de la cooperativa, ajustándose a lo previsto en los estatutos de la misma.

Otra medida es la suspensión, personas que dejan de trabajar durante determinado tiempo, de manera que se supone que la empresa va a superar su crisis en un período normalmente de unos meses. Temporalmente, se suspende la prestación de trabajo y se suspende el salario. Las personas afectadas, ven compensada mediante la correspondiente prestación por desempleo, esa merma económica, en este caso total, porque pierden totalmente el salario durante un tiempo.

La suspensión sí está prevista expresamente en la ley de cooperativas, en términos similares a la legislación laboral. La asamblea debe decidir si se produce o no la suspensión y qué personas pasan a la situación de suspensión.

Llegamos así a la medida más trascendental, pasando de la flexibilidad interna a la externa: el despido. El Derecho del Trabajo, en situaciones de crisis, prevé despidos individuales o colectivos. La principal diferencia es que, en el despido colectivo, las medidas deben ser negociadas con la representación de trabajadoras y trabajadores, aunque si no hay acuerdo la empresa unilateralmente puede proceder al despido, $\mathrm{y}$ a las personas afectadas solo les queda la posibilidad de demanda judicial.

En el caso del Derecho Cooperativo, como estamos ante la medida más importante y más drástica, sí que la ley de cooperativas —en este caso la Ley Vasca de Cooperativas - recoge expresamente el supuesto de la baja obligatoria, que es el equivalente al despido. Y aquí hay que subrayar un elemento. La ley habla de "reducción definitiva de puestos de trabajo», "para mantener la viabilidad económica de la cooperativa». 
El Estatuto de los Trabajadores, en sus primeras redacciones, sí que recogía que, para proceder a un despido de personas asalariadas, debería estar justificada esa medida, por ser de alguna manera inevitable para mantener la viabilidad económica futura de la cooperativa. Con los años esa previsión ha desaparecido.

Hemos observado que el Derecho del Trabajo prevé, además del despido, diversas medidas de flexibilidad interna. En situaciones de crisis, las empresas capitalistas a las que se aplica el Derecho Laboral, ¿qué pueden hacer? Pueden adoptar, con total discrecionalidad, cualquiera de las medidas mencionadas.

\section{Conclusión}

En el Derecho del Trabajo, en ninguna parte, ni en el Estatuto de los Trabajadores, ni en su desarrollo reglamentario, ni en la jurisprudencia, se indica que el despido deba ser la última medida. El despido es una más de las alternativas. Tenemos un catálogo, un menú y las empresas pueden elegir cualquier plato del menú. La flexibilidad interna y la externa se sitúan al mismo nivel. No hay ninguna cláusula que relegue el despido a medida indeseable o subsidiaria. No es una medida subsidiaria, es una medida alternativa.

Sin embargo en Derecho Cooperativo, como acabamos de ver, se permite únicamente la baja obligatoria (despido) cuando la situación sea de tal entidad, de tal gravedad, que sea una medida adecuada para mantener la viabilidad económica de la cooperativa. Se trata de la subsidiariedad de la baja obligatoria en el caso cooperativo. Despido como última ratio, mientras en el caso de Derecho Laboral, el despido puede ser y muchas veces lo es, la primera medida.

Además del elemento estrictamente jurídico, hay que tener en cuenta que, en las cooperativas, las bajas obligatorias (despidos), se deciden en asamblea, de manera que unos socios despiden a otros. Ante la dureza de ese escenario, la tendencia suele ser la de adoptar otras medidas de flexibilidad interna, que no impliquen sacrificar el empleo de compañeras y compañeros.

En las cooperativas, al contrario de lo que puede suceder, porque el Derecho Laboral lo permite, en las sociedades de capital, el empleo no se valora como coste productivo, que se podría suprimir para mejorar la cotización de la empresa.

Cuando se permite, en el caso del Derecho Laboral, despedir aunque la empresa tenga beneficios, se está tratando el empleo como mero coste productivo.

Por el contrario, si las cooperativas de trabajo asociado nacen para proporcionar empleo a las personas que las constituyen, están satisfaciendo su derecho al trabajo. 